\title{
Analisis Pengelolaan Logistik dalam Penanganan Darurat Bencana Gempa Bumi Di BPBD Kabupaten Sumbawa 2018
}

\author{
Aminah $^{1, a)}$, Eko Teguh Paripurno ${ }^{1)}$, Puji Lestari ${ }^{1)}$ \\ ${ }^{1)}$ Magister Manajemen Bencana, FakultasTeknologi Mineral, Universitas Pembangunan Nasional "Veteran" Yogyakarta

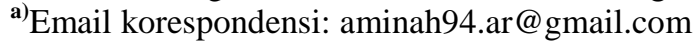

\begin{abstract}
ABSTRAK
Tahun 2018 Kabupaten Sumbawa mengalami gempa dengan kekuatan 6,9 SR sehingga tmengakibatkan15 kecamatan mengalami dampak bencana gempa bumi, total kerusakan sebanyak 7532 unit rumah rusak, 4932 mengalami rusak berat, 1395 rusak sedang dan sebanyak 1205 rusak ringan, menyebakan 38 orang cidera, dan 4 orang meninggal. Saat terjadi bencana kegiatan penanganan darurat yang dilakukan selain evakuasi masyarakat serta pertolongan darurat juga dilakukan penyediaan logistik. Oleh karena itu, berdasarkan peraturan yang berlaku, BPBD sebagai penanggungjawab dalam menanggulangi bencana perlu melakukan pengelolaan logistik guna terpenuhinya kebutuhan korban gempa. Tujuan penelitian ini yaitu menganalisis pengelolaan logistik yang dilakukan oleh BPBD Kabupaten Sumbawa. Metode yang digunakan yaitu pendekatan kualitatif karena ingin menganalisis kegiatan pengelolaan logistik dalam menjalankan Peraturan pengelolaan logistik sesuai yang telah ditetapkan. Berdasarkan hasil analisis menunjukkan bahwa BPBD dalam mengelola logistik belum menerapkan prinsip tepat jumlah, tepat waktu, dan tepat pelaporan sesuai dengan peraturan BNPB Nomor 4 Tahun 2018 tentang Sistem Manajemen Logistik dan Peralatan.
\end{abstract}

Kata kunci: BPBD Kabupaten Sumbawa; gempa bumi 2018; pengelolaan logistik

\begin{abstract}
In 2018, the Sumbawa Regency experienced an earthquake with a magnitude of 6.9, resulting in 15 sub-districts experiencing the impact of the earthquake, a total of 7532 housing units were damaged, 4932 were heavily damaged, 1395 were moderately damaged and as many as 1205 were lightly damaged, causing 38 people injured, and 4 people die. When disaster strikes, emergency response activities carried out in addition to community evacuation and emergency relief, logistics is also provided. Therefore, based on applicable regulations, BPBD as the person responsible for disaster management needs to manage logistics in order to meet the needs of earthquake victims. The research objective is analyzing logistics management carried out by the Sumbawa Regency BPBD. The method used is a qualitative approach because it wants to analyze logistics management activities in carrying out the logistics management regulations as specified. Based on the results of the analysis shows that BPBD managing logistics has not yet applied the principles of exact amount, on time, and proper reporting in accordance with BNPB regulation No. 4 of 2018 concerning Logistics and Equipment Management Systems.
\end{abstract}

Keywords: Sumbawa BPBD; earthquakes; logistics management

\section{PENDAHULUAN}

Pengertian bencana berdasarkan Undang-Undang Nomor 24 Tahun 2007 adalah peristiwa atau rangkaian peristiwa yang mengancam dan mengganggu kehidupan dan penghidupan masyarakat yang disebabkan oleh faktor alam atau faktor non alam maupun faktor manusia sehingga mengakibatkan timbulnya korban jiwa manusia, kerusakan lingkungan, kerugian harta benda, dan dampak psikologis.

Kabupaten Sumbawa merupakan salah satu daerah yang mengalami gempa yang cukup besar pada 19 Agustus 2018 dengan kekuatan 6.9 Skala Richter. Gempa kemudian terus terjadi beberapa kali lagi. Untuk mengantisipasi dampak kepada masyarakat akibat kondisi yang buruk diperlukan upaya yang cepat dan tepat dalam rangka meminimalisir dampak akibat gempa. Pada minggu pertama akan difokuskan pada upaya pencarian dan penyelamatan korban, pemenuhan kebutuhan dasar pengungsi, membangun tenda pengungsian, serta pelayanan kesehatan. Setiap daerah, pemerintah daerah biasanya telah membentuk tim yang jika terjadi bencana akan ikut serta membantu menyelamatkan korban bencana, mengelola distribusi bantuan bencana alam serta mendampingi sampai masa pemulihan. Masalah yang sering muncul setiap terjadi bencana adalah bantuan yang menumpuk di satu tempat sehingga menimbulkan kemarahan dari masyarakat atau korban yang terdampak bencana, atau pendistribusian yang terlambat akibatnya kurangnya pendataan dan transportasi sehingga bantuan logistik yang didistribusikan menjadi tidak merata dimana salah satu daerah mendapat bantuan lebih dan daerah lainnya kekurangan bantuan.Studi yang telah dilakukan oleh Kusumastuti, Wibowo, dan Insanita (2010) menunjukkan bahwa masih ada kesenjangan antara harapan korban bencana dan waktu respon sebenarnya dalam praktek logistik bencana di Indonesia.Logistik merupakan kegiatan pokok maupun penunjang yang diselenggarakan dan digunakan secara fisik dalam wujud benda (Irmawati \& PGDHS, 2015), sedangkan logistik 
menurut Peraturan BNPB Nomor 10 Tahun 2012, suatu kebutuhan dasar manusia yang berwujud dapat digunakan terdiri atas pangan, sandang dan papan atau turunannya. Pengelolaan bantuan logistik pada status keadaan darurat menurut Perka BNPB Nomor 10 Tahun 2012 merupakan suatu kegiatan mengelola barang bantuan penanggulangan bencana yang dilakukan secara terpadu. Pendekatan terpadu terdiri dari pencarian sumber, pengadaan logistik, penjaminan kualitas, pengemasan, pengiriman pengangkutan, penyimpanan di gudang dan pengelolaan persediaan logistik, dimana banyak melibatkan pelaku yang memiliki aktivitas berbeda. Dengan keadaan tersebut, setiap pelaku yang terlibat harus terkoordinasi, perlu ditetapkannya pengelolaan dan dilakukan pemantauan yang tepat guna memastikan bahwa semua bantuan dijaga hingga bantuan tersebut didistribusikan sampai pada penerima di tingkat rumah tangga (kepala keluarga). Hellingrath \& Widera (2011) dan Widener \& Horner (2011) menyatakan bahwa infrastruktur, politik dan pemerintah menjadi tantangan utama dalam logistik. Salah satu masalah dalam logistik yaitu banyaknya infrastruktur yang belum memadai dari jalan yang rusak hingga minimnya pelabuhan untuk kapal logistik yang masuk.Peran pemerintah serta lembaga terkait sangat dibutuhkan dalam mengambil keputusan menjadi hal penting dalam sistem penanggulangan bencana.Hal ini menunjukkan peran koordinasi yang efektif sangatlah penting dalam pelaksanaan pengelolaan logistik berdasarkan pendapat Rossem dan Krukkert (2010) bahwa koordinasi antara semua pihak yang terlibat dalam kegiatan bantuan logistik menjadi faktor penting dalam logistik bencana. Indonesia dalam menanggulangi bencana memiliki sistem yang di atur dalam UU Nomor 24 Tahun 2007 tentang penanggulangan bencana yang menyebutkan BPBD bertindak sebagai koordinator dalam suatu bencana. Untuk mengendalikan dan menanggulangi risiko dan dampak bencana khususnya gempa, BPBD Sumbawa memiliki Tim Tanggap Darurat Bencana (TAGANA) yang bertugas dalam pengelolaan logistik di posko darurat bencana.Dihimpun dari berita online Republika.co.id yang diakses pada 10 Desember 2018, pada saat terjadi bencana gempa 2018, BPBD mulai melakukan pendistribusian bantuan yang tersedia.Kendati demikian BPBD dan pihak terkait masih kekurangan bantuan di Kabupaten Sumbawa, dan yang menjadi kebutuhan paling mendesak adalah tenda, terpal dan logistik. Masalah lainnya yaitu pendistribusian bantuan di setiap daerah tidak merata.Tidak meratanya pendistribusian disebabkan karena kurangnya koordinasi antara lembaga-lembaga bantuan yang memberikan bantuan di daerah tersebut.

Dalam operasi darurat pengelolaan bantuan logistik membutuhkandukungan organisasidan pelaksanaan operasi status keadaan darurat dengan tujuan memastikan ketepatan waktu dan efisiensi. Dukungan bantuan logistik sesuai prinsipnya harus tepat waktu, tepat lokasi, tepat sasaran, tepat kualitas, tepat kuantitas dan sesuai kebutuhan. Pengelolaan bantuan logistik menjadi salah satu unsur penting yang harus diperhatikan sehingga dapat dilakukan secara efektif dan efisien pada saat status keadaandarurat bencana.

Penelitian terdahulu terkait logistic oleh Moh. Apriawan (2016) bertujuan untuk mengetahui faktor-faktor yang mempengaruhi pengendalian logistik bencana di Sulawesi Tengah serta untuk mengetahui faktor yang menjadi prioritas pengendalian logistik di Provinsi Sulawesi Tengah, dengan metode penelitian yang digunakan Analytical Hierarchy Process (AHP). Hasil penelitian menunjukkan 5 kriteria yang mempengaruhi penanganan logistik bencana di Provinsi Sulawesi Tengah yaitu (1) Sumber Daya Manusia (2) Ketidakpastian (3) Kolaborasi dan kerjasama (4) Sarana Prasarana dan (5) Pendanaan, yang menjadi prioritas utama adalah sumber daya manusia.

Selain itu, ada penelitian lainnya yang dilakukan oleh Stella dan Djazuly (2018), dengan tujuan penelitian persediaan obat di apotek logistik Rumah Sakit Siti Khodijah Sepanjang. Penelitian tersebut adalah penelitian deskriptif dengan desain cross sectional dengan observasi dan wawancara. Hasil penelitian menunjukkan kegiatan perencanaan, pengadaan, distribusi, dan penyimpanan dilakukan tidak cukup efektif sehingga menyebabkan stagnan dan kehabisan obat, juga evaluasi yang tidak memadai.

Sedangkan penelitiannya lainnya terkait logistik oleh Raden (2017) menunjukkan kegiatan pergudangan logistik dengan tujuan mengetahui jumlah dan jenis persediaan logistik dan peralatan di gudang dengan cepat dan tepat untuk masa tanggap bencana, dilakukan dengan pendekatan kualitatif. Hasil penelitian menunjukkan kegiatan pengelolaan pergudangan yang dilakukan dalam menjalankan pedoman pergudangan oleh BNPB telah sesuai dengan peraturan BNPB.

Berdasarkan analisa tersebut, maka peneliti tertarik untuk menganalisis kegiatan pengelolaan logistiksaat bencana gempa bumi 2018 di Kabupaten Sumbawa dengan tujuan melihat kesesuaian kegiatan di lapangan dengan peraturan kebencanaan.

\section{METODE}

Jenis penelitian ini menggunakan deskriptif kualitatif, dengan melakukan wawancara serta penelahaan dokumen berupa peraturan kebencanaan. Metode ini digunakan sebagai pembanding kegiatan di lapangan dengan standar peraturan kebencanaan.

Teknik penentuan informan digunakan dalam penelitian ini adalah dengan cara purposive sampling yakni mencari orang-orang yang lebih mengetahui, memahami, atau dapat memberikan informasi tentang informasi yang diketahui lebih banyak dalam memberikan informasi yang dibutuhkan 
JMEL, Volume 4 Nomor 1, 2020

\section{HASIL DAN PEMBAHASAN}

\subsection{Pengelolaan Logistik}

Hasil analisis kegiatan pengelolaan logistik BPBD Kabupaten Sumbawa pada Tahun 2018 disajikan pada Tabel 1.

Tabel 1. Hasil Analisis Kegiatan Pengelolaan Logistik BPBD Kabupaten Sumbawa Tahun 2018

\begin{tabular}{ll}
\hline Indikator & Hasil wawancara \\
\hline & "Dalam penanganan darurat bencana \\
& Kabupaten Sumbawa mempunyai \\
kebijakan berupa Peraturan Daerah & Kabupaten Sumbawa Nomor 5 Tahun \\
& 2016 tentang Penyelenggaraan \\
& Penanggulangan Bencana, dalam \\
keraturan tersebut saat terjadi bencana & BPBD memanfatkan sumber daya yang \\
ada mengerahkan sumber daya & manusia, pengerahan peralatan dan \\
& logistik sehingga lebih memudahkan \\
& saat penanganan darurat bencana"
\end{tabular}

\section{Peraturan terkait kebencanaan}

Kebijakan yang dimiliki oleh Kabupaten Sumbawa telah sesuai dengan UndangUndang Nomor 24 Tahun 2007 tentang Penanggulangan Bencana, yang menyebutkan Badan Penanggulangan Bencana Daerah mempunyai tugas menetapkan pedoman dan pengarahan sesuai dengan kebijakan pemerintah daerah, namun dalam Peraturan Daerah yang dimiliki oleh Kabupaten Sumbawa belum menjelaskan secara rinci tahap pengelolaan logistk saat bencana terjadi.

\begin{abstract}
"Saat itu kita melakukan perencanaan untuk menentukan kebutuhan apa saja yang dibutuhkan lalu melakukan pengadaan barang logistik dari bantuan pemerintah ditambah dengan APBD daerah, dari dunia usaha juga dari masyarakat, setelah ada bantuan di simpan di gudang. Untuk gudang penyimpanan, BPBD memiliki gudang yang luasnya terbatas sehingga kebutuhan lainnyadisimpan di gudanggudang posko, gudang Pemda, dan Bulog. Pendistribusian bantuan menggunakan moda transportasi”
\end{abstract}

Berdasarkan Perka BNPB Nomor 4 Tahun 2018 tentang Sistem Manajemen Logistik dan Peralatan, dalam menanggulangi bencana yang memuat kegiatan perencanaan, pengadaan, pergudangan, dan pendistribusian, bahwa BPBD Kabupaten Sumbawa menjadi pihak yang bertanggungjawab kemudian bantuan disalurkan ke kecamatan-kecamatan terdampak lalu kepala desa dan menyalurkan bantuan ke posko-posko pengungsian, namun pendapat dari masyarakat, mereka cukup lama dalam menerima bantuan dan bantuan yang datang menumpuk di suatu pos komando penanggulangan bencana.

\footnotetext{
Perencanaan merupakan kegiatan melalui identifikasi kebutuhan, inventarisasi ketersediaan, pengumpulan data, dan analisis untuk menghasilkan standar minimal kebutuhan dalam penanggulangan bencana.
}

Saat bencana gempa BPBD Kabupaten Sumbawa menugaskan Tim Reaksi Cepat untuk mengidentifikasi kebutuhan masyarakat serta banyak pihak yang ikut serta membantu saat penanganan gempa Sumbawa, untuk logistik di Posko ada TAGANA, TNI, Polisi, Pramuka
Kegiatan perencanaan yang dilakukan telah dilaksanakan sesuai dengan Perka BNPB Nomor 13 Tahun 2008 tentang Pedoman Manajemen Logistik dan Peralatan Penanggulangan Bencana, dimana inventarisasi kebutuhan dihimpun dari Tim Reaksi Cepat juga bidang logistik yang beranggotakan para 
Proses pengadaan/penerimaan bantuan logistik pada status keadaan darurat bencana dimulai dengan melakukan pencatatan dan pengecekan, sumber bantuan yang diperoleh, waktu diterimanya bantuan, jenis dan jumlah bantuan, cara penyimpanan, transporter yang digunakan, serta sasaran penerima bantuan, yang dilaksanakan oleh koordinator bidang logistik.
Pengadaan barang logistik dari bantuan pemerintah ditambah dengan APBD daerah, juga dari lembaga usaha namun kendala yang dihadapi yaitu pihak pendonor tidak melakukan pencatatan dan beberapa pihak yang langsung menyalurkan bantuan ke tenda pengungsian korban tanpa melakukan pelaporan terlebih dahulu pada pihak posko darurat/BPBD.

\section{Pergudangan merupakan} pengelolaan penerimaan, penyimpanan, pemeliharaan, dan pengeluaran logistik dan peralatan di gudang. petugas perwakilan dari instansi, dinas/lembaga/organisasirelawan sesuai dengan Perka BNPB Nomor 10 Tahun 2012 tentang Pengelolaan Bantuan Logistik pada Status Keadaan Darurat Bencana. Kegiatan pengadaan bantuan diperoleh dari Pemerintah serta lembaga usaha sesuai dengan Perka BNPB Nomor 10 Tahun 2012 tentang Pengelolaan Bantuan Logistik pada Status Keadaan Darurat Bencana yang menyebutkan sumber penerimaan logistik dapat diperoleh dari dalam dan luar negeri terdiru dari masyarakat, pemerintah dan pemerintah daerah serta dunia usaha.
Bantuan yang datang, disimpan di gudang BPBD, gudang-gudang posko, gudang Pemda, dan Bulog
Kegiatan pergudangan yang dilaksanakan telah sesuai dengan Perka BNPB 10 Tahun 2012 yaitu tentang Pengelolaan Bantuan Logitstik pada Status Keadaan Darurat Bencana, dengan memperhatikan penempatan penyimpanan yang aman

Pendistribusian merupakan
sistem penyaluran dan
penyerahan logistik dan
peralatan dari daerah asal ke
daerah tujuan sampai pada
sasaran yang dituju.

Pendistribusian dilakukan oleh Pusdalops BPBD Kabupaten Sumbawa menggunakan truk didistribusikan ke kecamatan, kepala desa lalu ke masyarakat. Kendala pada ketersediaan kendaraan distribusi yang digunakan serta ukuran truk yang tidak mencukupi pengangkutan logistik sehingga bantuan yang datang sedikit terhambat
Kegiatan pendistribusian yang dilakukan sesuai dengan Perka BNPB Nomor 10 Tahun 2012 tentang Pengelolaan Bantuan Logistik pada Status Keadaan Darurat Bencana, dimana setelah mendapat persetujuan dari pejabat berwenang. bantuan logistik disalurkan ke tempat tujuan selanjutnya didistribusikan kepada korban sesuai dengan data permintaan.

\begin{abstract}
"Mekanisme pemantauan dan evaluasi dilakukan oleh semua pihak terkait, misalnya ada pasien yang harus ditangani, namun untuk bantuan logistik pemberi bantuan biasanya langsung memberikan bantuan ke satu tempat pengungsian tanpa melapor terlebih dahulu ke pihak posko sehingga satu tempat kelebihan bantuan dan tempat lainnya kekurangan bantuan"
\end{abstract}

\section{Kegiatan}

pengawasan terkait logistik tetap dilakukan oleh BPBD agar terjaminnya kebutuhan korban pengungsi, namun karena kurangnya kerja sama antara pemberi bantuan serta petugas penerima bantuan menjadi salah satu kendala dalam pengawasan pengelolaan bantuan.

\section{Pengawasan}

Analisis temuan pada pelaksanaan pengelolaan logistik yang telah dilakukan di BPBD Kabupatem Sumbawa meliputi :

\section{Kebijakan}

Kebijakan menurut Titmuss (2010) sebagai prinsip-prinsip yang telah diatus dalam tindakan yang mengarah pada tujuan-tujuan tertentu. Dalam pengelolaan logistik bencana telah diatur dalam beberapan kebijakan diantaranya Perka BNPB Nomor 4 Tahun 2009 tentang Pedoman Bantuan Logistik, Perka BNPB Nomor 10 Tahun 2012 tentang Pengelolaan Bantuan Logistik pada Status Keadaan Darurat Bencana, Perka BNPB Nomor 4 Tahun 2018 tentang Sistem Manajemen Logistik dan Peralatan. Kabupaten Sumbawa memiliki kebijakan terkait bencana namun tidak memuat secara rinci kegiatan dalam pengelolaan logistik sehingga dibutuhkan pembaruan dalam membuat kebijakan.

\section{Keterampilan}

Katz (2009) menyatakan keterampilan secara umum dapat dibagi menjadi tiga bagian pokok, yaitu technical skill, conceptual skill and human skill.Technical skill adalah kemampuan untuk menggunakan alat-alat, prosedur dan teknik suatu bidang khusus.Petugas yang melaksanakan tugasnya harus memiliki kemampuan teknis yang cukup, 
sedangkan keterampilan konseptual adalah kemampuan mental untuk melakukan koordinasi dan memadukan semua kepentingan dan kegiatan pengelolaan logistik.Adapun keterampilan dalam pengelolaan logistik dilakukan oleh petugas terdiri dari kegiatan perencanaan sampai pendistribusian bantuan.

\section{1) Perencanaan}

Strategi untuk perencanaan pengelolaan logistik dilakukan dengan identifikasi dan analisis kebutuhan serta pengerahan sumber daya. Identifikasi dan analisis kebutuhan, kegiatan pertama yang harus dilakukan dalam pengelolaan logistik, ini dilakukan guna mengetahui jumlah dan jenis bantuan dan peralatan yang dibutuhkan, mengetahui jumlah korban terdampak bencana yang membutuhkan bantuan, metode pendistribusian yang digunakan, serta menentukan waktu penyampaian bantuan.

\section{2) Pengadaan dan /penerimaan logistik}

Kegiatan ini dimulai dengan pencatatan atau inventarisasi kebutuhan logistik maupun peralatan, sumber bantuan yang diterima, jenis dan jumlah bantuan yang diberikan, namun dalam pengadaan logistik masih terdapat kekurangan pada banyak hal, yaitu pengadministrasian logistik masih dilakukan seadanya tanpa mengikuti ketentuan, pihak pendonor yang memberikan bantuan tanpa ada pencatatan serta pihak-pihak yang langsung menyalurkan bantuan pada tenda pengungsian tanpa ada koordinasi dengan pihak yang menangani logistik. Permasalahan-permasalahan tersebut akan menghambat kelancaran operasi pengelolaan logistik. Untuk penanggulangan bencana, Pemerintah Kabupaten Sumbawa telah membentuk Badan Penanggulangan Bencana Daerah yang tertuang dalam Peraturan Bupati Nomor 53 Tahun 2010 dan telah dirubah dengan Peraturan Bupati Nomor 10 Tahun 2012. Adapun lembaga yang terlibat dalam kegiatan logistik antara lain Taruna Siaga Bencana (TAGANA), Pramuka, Palang Merah Indonesia (PMI) Kabupaten Sumbawa, serta relawan kabupaten dan forum pengurangan risiko bencana di Desa Tangguh Bencana (Destana)

\section{3) Pergudangan}

Merupakan proses penyimpanan dengan menempatkan logistik dan peralatan yang diterima. Dalam hal ini BPBD Kabupaten Sumbawatelah mengikuti ketentuan penyimpanan dan pergudangan bantuan logistik yang disesuaikan dengan pemilihan tempat, kapasitas gudang yang tersedia dan fasilitas penyimpanan, serta melakukan pengamanan dan keselamatan sesuai dengan ketentuan yang berlaku.

\section{4) Pendistribusian}

Menurut Perka BNPB Nomor 13 Tahun 2008 tentang Pedoman Manajemen Logistik dan Peralatan Penanggulangan Bencana, perencanaan pendistribusian terdiri dari data: siapa sajapihak yang akan menerima bantuan, bantuan logistik dan peralatan yang diprioritaskan, waktu penyampaian bantuan yang dilakukan, lokasi, cara penyampaian, transportasi yang digunakan, siapa pihak yang bertanggung jawab atas penyampaian tersebut. Dalam hal ini pendistribusian dilakukan oleh Pusdalops BPBD dengan transportasi yang digunakan truk distribusi, jumlah dan ukuran truk dapat menjadi penghambat kegiatan distribusi dimana bantuan yang diterima tidak tepat waktu.

\section{Pengawasan}

Untuk mengetahui jalannya suatu pekerjaan serta perbaikan yang dilakukan agar tidak terjadi kesalahan dibutuhkan pengawasan. Pengawasan menjadi ruang lingkup pedoman bantuan logistik penanggulangan bencana.Apabila pengawasan tidak dilaksanakan sesuai yang ditetapkan dikhawatirkan akan menimbulkan penyimpangan

Dari hasil wawancara yang dilakukan kepada pegawai BPBD Kabupaten Sumbawa dengan membandingkan kegiatan di lapangan dengan peraturan kebencanaan tentang pengelolaan logistik, telah dilaksanakan sesuai aturan mulai dari pengadaan bantuan sampai pendistribusian dan BPBD menjadi pihak yang bertanggungjawab kemudian bantuan disalurkan ke kecamatan-kecamatan terdampak lalu kepala desa dan menyalurkan bantuan ke posko-posko pengungsian masyarakat dan berdasarkan Peraturan BNPB Nomor 4 Tahun 2018 tentang Sistem Manajemen Logistik dan Peralatan dilaksanakan dengan prinsip tepat jenis, tepat jumlah, tepat kualitas, tepat waktu, tepat sasaran, tepat biaya dan tepat pelaporan. Tahapan manajemen logistik bantuan yang dilakukan oleh BPBD Kabupaten Sumbawa belum berjalan sesuai dengan prinsip standar peraturan BNPB yaitu tepat jumlah, tepat waktu, dan tepat pelaporan karena tidak semua pihak yang terlibat melakukan pencatatan dan pelaporan penerimaan bantuan dan kendaraan transportasi untuk distribusi bantuan yang digunakan masih kurang sehingga bantuan yang diterima mengalami keterlambatan. Kegiatan yang dilakukan BPBD Kabupaten Sumbawa berdasarkan rencana kontijensi banjir Tahun 2018 dapat dilihat pada Tabel 2. 
Dari Tabel 1 dilihat bahwa kegiatan penangan darurat dalam bidang logistic yang dilakukan oleh BPBD Kabupaten Sumbawa telah sesuai dengan ketentuan yang dituangkan ke dalam Peraturan BNPB Nomor 2 Tahun 2018 tentang Penggunaan Dana Siap Pakai, namun kegiatan pengelolaan logistik tersebut khusus bencana banjir sehingga saat bencana gempa terjadi kegiatan pengelolaan tidak begitu mengacu pada rencana kontijensi yang dimiliki karena tidak memuat kegiatan saat bencana gempa.

Tabel 2. Kegiatan yang Dilakukan BPBD Kabupaten Sumbawa Berdasarkan Rencana Kontijensi Banjir 2018

\begin{tabular}{|c|c|c|c|c|c|c|}
\hline \multirow[t]{2}{*}{ No } & \multirow[t]{2}{*}{ Jenis Kegiatan } & \multicolumn{2}{|c|}{ Pelaku } & \multicolumn{2}{|c|}{ Waktu Pelaksanaan } & \multirow[t]{2}{*}{ Durasi } \\
\hline & & $\begin{array}{l}\text { Instansi / } \\
\text { Lembaga }\end{array}$ & $\begin{array}{l}\text { Penanggungj } \\
\text { awab }\end{array}$ & Waktu dimulai & $\begin{array}{l}\text { Waktu } \\
\text { Berakhir }\end{array}$ & \\
\hline 1 & $\begin{array}{l}\text { Menyediakan tempat } \\
\text { pengungsian yang layak }\end{array}$ & $\begin{array}{l}\text { Dinas Sosial, } \\
\text { BPBD, PMI, } \\
\text { PRAMUKA, } \\
\text { Bulog, Dinas }\end{array}$ & BPBD & $\begin{array}{l}\text { Setelah } \\
\text { aktivasi posko }\end{array}$ & $\begin{array}{l}\text { Berakhirnya } \\
\text { masa } \\
\text { tangapdarurat }\end{array}$ & 14 hari \\
\hline 2 & $\begin{array}{l}\text { Menyediakan berbagai } \\
\text { kebutuhan pangan dan } \\
\text { peralatan bayi }\end{array}$ & Pendidikan & Dinsos & $\begin{array}{l}\text { Setelah ada } \\
\text { pengungsian }\end{array}$ & $\begin{array}{l}\text { Selama masa } \\
\text { tanggapdaruat }\end{array}$ & 14 hari \\
\hline 3 & $\begin{array}{l}\text { Menyediakan obat- } \\
\text { obatan dan pelayanan } \\
\text { kesehatan }\end{array}$ & & Dinkes & $\begin{array}{l}\text { Setelah ada } \\
\text { pengungsian }\end{array}$ & $\begin{array}{l}\text { Selama masa } \\
\text { tanggap daruat }\end{array}$ & 14 hari \\
\hline 4 & $\begin{array}{l}\text { Menyediakan peralatan } \\
\text { untuk pendidikan darurat } \\
\text { (pensil, buku, } \\
\text { penghapus) }\end{array}$ & & Dikbud & $\begin{array}{l}\text { Setelah } \\
\text { kejadian }\end{array}$ & $\begin{array}{l}\text { Selamamasa } \\
\text { tanggap } \\
\text { darurat }\end{array}$ & 14 hari \\
\hline 5 & $\begin{array}{l}\text { Menyediakan perlatan } \\
\text { memasak, peralatan } \\
\text { mandi, selimut, dan } \\
\text { kebutuhan khusus wanita }\end{array}$ & $\begin{array}{l}\text { PMI, tagana, } \\
\text { BPBD }\end{array}$ & Dinsos & $\begin{array}{l}\text { Setelah } \\
\text { kejadian }\end{array}$ & $\begin{array}{l}\text { Pengungsian } \\
\text { selesai }\end{array}$ & $\begin{array}{l}\text { Menyesuai } \\
\text { kan }\end{array}$ \\
\hline
\end{tabular}

\section{KESIMPULAN}

Kegiatan pengelolaan logistik yang dilakukan oleh BPBD Kabupaten Sumbawa belum memiliki rencana kontijensi khusus gempa sehingga penanganan logistik yang dilakukan dilapangan seadanya sehinggaperlunya dibuat rencana kontijensi lainnya yang memuat bencana gempa. Sepanjang melakukan kegiatan pengelolaan logistik saat penanganangan darurat gempa 2018, BPBD Kabupaten Sumbawa sebagian besar telah mengikuti peraturan terkait logistik. Pengawasan menjadi indikator yang tidak dapat dikendalikan oleh pihak yang terlibat, karena kurangnya koordinasi dari pihak pendonor dalam melakukan pencatatan bantuan logistik yang diberikan langsung ke suatu wilayah tertentu tanpa melakukan pelaporan kepada BPBD menjadi penghambat kelancaran operasi pengelolaan logistik.Sehingga pengawasan dan pengendalian dengan teliti dan obyektif perlu ditingkatkan lagi agar tujuan pemenuhan kebutuhan logistik korban bencana dapat tercapai.Serta perlu dilakukan pengusulan penambahan kendaraan distribusi bantuan agar pengelolaan logistik dapat dilaksanakan secara cepat, tepat, terpadu, efektif, efisien, dan akuntabel.

\section{DAFTAR PUSTAKA}

Hellingrath, B., dan Widera, A. (2011). Survey On Major Challenge in Humanitarian Logistics. Proceedinga of the 8th International ISCRAM Conference, 1-5.

Irmawati, L. I., \& PGDHS, A. S. M. (2015). Manajemen Logistik Farmasi. Buku Ajar: Pedoman Praktis S1 Administrasi Rumah Sakit. Institut Ilmu Kesehatan-University Press. 
Katz, R.L. (2009). Skill of an effective administrator. Harvard Business Review Press.

Kusumastuti, R.D., Wibowo, S.S., dan Insanita, R.. (2010). Relief logistics practices in Indonesia: A survey. Diakses pada 4 November 2019, dari http://papers.ssrn.com/sol3/papers.cfm?abstract_1681217

Moh. Apriawan. (2016). Analisis Penentuan Prioritas Pengendalian Logistik Bencana di Sulawesi Tengah. Jurnal Ilmu Manajemen, 2 (1). Universitas Tadulako.

Perka BNPB Nomor 10 Tahun 2012 Tentang Pengelolaan Bantuan Logistik Pada Status Keadaan Darurat Bencana.

Perka BNPB Nomor 2 Tahun 2018 Tentang Penggunaan Dana Siap Pakai.

Perka BNPB Nomor 24 Tahun 2010 Tentang Pedoman Penyusunan Rencana Operasi Darurat

Perka BNPB Nomor 4 Tahun 2009 Tentang Pedoman Bantuan Logistik.

Perka BNPB Nomor 4 Tahun 2018 Tentang Sistem Manajemen Logistik Dan Peralatan.

Perka BNPB Nomor 6 Tahun 2009 Tentang Pedoman Pergudangan.

Raden Didiet, RH., dkk. (2017). Pengelolaan Gudang Logistik Kemanusiaan BNPB. Jurnal Manajemen Industri dan Logistik, 1 (2). Politeknik APP Jakarta.

Rossum, J.V., \& Krukkert, R. (2010). Disaster Manajement in Indonesia: Logistical coordination and cooperation to create effective relief operations. Journal of Industrial Engineering, 12 (1).

Stella Herliantine Febreani dan Djazuly Chalidyanto.2018. Pengelolaan Sediaan Obat pada Logistik Farmasi Rumah Sakit Umum Tipe B di Jawa Timur. Jurnal Adminitrasi Kesehatan Indonesia, 4 (2).

Widener, M. J., dan Horner, M. W. (2011). A Hierarchical Approach to Modeling Hurricane Disaster Relief Goods Distribution. Journal of Trasport Geography, 19, 821-828. 